\title{
An estimate of global glacier volume
}

\author{
A. Grinsted \\ College of Global Change and Earth System Science, Beijing Normal University, Beijing, China \\ Centre for Ice and Climate, Niels Bohr Institute, University of Copenhagen, Denmark
}

Correspondence to: A. Grinsted (ag@glaciology.net)

Received: 27 July 2012 - Published in The Cryosphere Discuss.: 3 September 2012

Revised: 18 December 2012 - Accepted: 26 December 2012 - Published: 30 January 2013

\begin{abstract}
I assess the feasibility of using multivariate scaling relationships to estimate glacier volume from glacier inventory data. Scaling laws are calibrated against volume observations optimized for the specific purpose of estimating total global glacier ice volume. I find that adjustments for continentality and elevation range improve skill of areavolume scaling. These scaling relationships are applied to each record in the Randolph Glacier Inventory, which is the first globally complete inventory of glaciers and ice caps. I estimate that the total volume of all glaciers in the world is $0.35 \pm 0.07 \mathrm{~m}$ sea level equivalent, including ice sheet peripheral glaciers. This is substantially less than a recent stateof-the-art estimate. Area-volume scaling bias issues for large ice masses, and incomplete inventory data are offered as explanations for the difference.
\end{abstract}

\section{Introduction}

Globally, glaciers are shrinking and are contributing to global sea level rise (Leclercq et al., 2011; Cogley, 2012). Their potential contribution to sea level rise is limited by their total volume. Regional sea level rise will depend strongly on the spatial pattern of ice mass loss (Mitrovica and Milne, 2003; Slangen et al., 2011). Further, glaciers are an important water resource in many regions. It is thus of great importance to estimate the volume of glaciers worldwide. It is presently not viable to measure the thickness and volume of all the remote glaciers on Earth, and glacier volumes for the vast majority of glaciers have therefore been estimated from empirical (but physically justified) scaling laws between glacier area and glacier volume (Bahr et al., 1997). Table 1 has a non-exhaustive list of scaling laws found in the literature. An additional complication has been that there has not been any globally complete glacier inventory and previous estimates have relied on upscaling of incomplete inventories (e.g. Radić and Hock, 2010). This has led to a wide range of estimates as reviewed in Cogley (2012). The IPCC (Intergovernmental Panel on Climate Change) TAR (Third Assessment Report) estimate of $\sim 50 \mathrm{~cm}$ sea level equivalent (SLE) (Church et al., 2001) was revised to about $30 \mathrm{~cm}$ SLE in the IPCC AR4 (Lemke et al., 2007; Cogley, 2012). Radić and Hock (2010) has since estimated a volume of about $60 \mathrm{~cm}$ SLE using scaling relationships, and Huss and Farinotti (2012) applied a novel physically based flux balance approach to estimate the global glacier volume to be $43 \mathrm{~cm}$ SLE. In this paper, I revisit the scaling laws used to estimate volume for individual glaciers, and apply them to the new globally complete Randolph Glacier Inventory (Arendt et al., 2012).

\section{Data}

The three large global glacier inventories were used in this study: The World Glacier Inventory (WGI) which has extensive metadata on 132000 glaciers and ice caps (WGMS and NSIDC, 2012). I also use the Global Land Ice Monitoring from Space (GLIMS) database which has glacier outlines and some metadata for 96000 glaciers and ice caps (Armstrong et al., 2012). Finally, I use the newly compiled Randolph Glacier Inventory v2 (RGI) which contains, primarily, 170000 glacier outlines with little additional metadata for each record. A series of semi-automated checks were applied to the inventory data to remove or correct for obvious reporting mistakes such as swapped maximum and minimum elevations or double reported polygons. Outlet glaciers from the Greenland ice sheet were removed from the WGI. The 
Table 1. Area-volume scaling laws found in the literature. Some of the cited studies operate with several relationships based on glacier type or region.

\begin{tabular}{|c|c|c|c|}
\hline & Glaciers & Ice caps & Comment \\
\hline Erasov (1968) & $0.027 \cdot A^{1.5}$ & \multirow{5}{*}{$0.04 \cdot A^{1.25}$} & Central Asia \\
\hline Yafeng et al. (1981) & $0.0361 \cdot A^{1.406}$ & & $\begin{array}{l}\text { As recalculated by Chen } \\
\text { and Ohmura (1990) }\end{array}$ \\
\hline Macheret and Zhuravlev (1982) & $0.0597 \cdot A^{1.12}$ & & Svalbard glaciers and ice caps \\
\hline Chizhov and Kotlyakov (1983) & & & From ice caps and ice sheets \\
\hline Macheret et al. (1984) & $0.0371 \cdot A^{1.357}$ & & \\
\hline Zhuravlev (1985) & $0.03 \cdot A^{1.36}$ & \multirow[t]{3}{*}{$k \cdot A^{1.26}$} & Estimated from figure \\
\hline Driedger and Kennard (1986) & $0.0218 \cdot A^{1.124}$ & & \\
\hline Zhuravlev (1988) & $0.048 \cdot A^{1.186}$ & & $\begin{array}{l}\text { As recalculated by Chen } \\
\text { and Ohmura (1990) }\end{array}$ \\
\hline Macheret et al. (1988) & $0.0298 \cdot A^{1.379}$ & \multirow{6}{*}{$\begin{array}{l}k \cdot A^{1.22} \\
k \cdot A^{1.25}\end{array}$} & Altai - Tien Shan mountains \\
\hline Chen and Ohmura (1990) & $0.0285 \cdot A^{1.357}$ & & Alps \\
\hline Meier and Bahr (1996) & $k \cdot A^{1.36}$ & & \\
\hline Bahr (1997) & $k \cdot A^{1.375}$ & & Physically justified exponents \\
\hline Bahr et al. (1997) & $0.0276 \cdot A^{1.36}$ & & Fit to 144 glaciers \\
\hline Van de Wal and Wild (2001) & $0.0213 \cdot A^{1.375}$ & & $\begin{array}{l}k \text { tuned to total sea level } \\
\text { from Warrick }(1996)\end{array}$ \\
\hline Shiyin et al. (2003) & $0.0395 \cot A^{1.35}$ & \multirow{4}{*}{$\begin{array}{l}0.0538 \cdot A^{1.25} \\
A^{[1.26-1.355]}\end{array}$} & Qilian and Tien Shan \\
\hline Radić et al. (2007) & $k \cdot A^{[1.56-2.90]}$ & & Simulated steady-state vs. transient \\
\hline Radić and Hock (2010) & $0.0365 \cdot A^{1.375}$ & & Based on earlier studies \\
\hline Huss and Farinotti (2012) & {$[0.024-0.042] \cdot$} & & $\begin{array}{l}\text { Separate relationship for each } \\
\text { RGI region }\end{array}$ \\
\hline Adhikari and Marshall (2012) & $k \cdot A^{[1.38-1.46]}$ & & Simulated transient vs. steady-state \\
\hline
\end{tabular}

spatial coverage of the databases is shown in Fig. 1. I adopt the regions defined by Arendt et al. (2012), which resemble those used by Radić and Hock (2010), but with some small differences.

I augment the RGI with additional data from GLIMS and WGI where it is possible to match records directly based on identifications. Unfortunately only $23 \%$ of the GLIMS records, and only $1 \%$ of the WGI records can be matched with RGI glaciers in this manner. In order to take advantage of the rich metadata in the WGI, I therefore also construct another global inventory where I start from WGI data, and then add GLIMS and RGI data successively. In order to avoid duplicates I exclude records based on matched identification numbers, and secondly based on a distance filter. Both glacier databases end up having $\sim 170000$ records globally. Unfortunately, it is evident from comparing the regional areas between the two databases that there are remaining deficiencies to be resolved with this WGI/GLIMS database (Table 2). For example, the two largest ice masses in Svalbard were excluded by the distance filtering.

I do not use WGI thickness data, as a high fraction of the reported values are the result of area-volume scaling relationships, and therefore should not be used to calibrate new scaling laws. Cogley (2012) compiled a database of available glacier volume observations where thickness has been measured. In this paper, I use an updated version of this database (see Supplement) containing area, volume and elevation range of 254 glaciers and ice caps (see Figs. 1, 2). This information is matched to inventory records where possible, but all volume records are retained for calibrating volume scaling laws. The volume database has a great degree of overlap with many of the studies listed in Table 1.

For GLIMS and RGI, I estimate the elevation range spanned by each glacier using the global digital elevation model (DEM) from the shuttle radar topography mission (SRTMv4; Jarvis et al., 2008) in $250 \mathrm{~m}$ resolution, and GTOPO30 (Global 30-Arc Second Elevation Data Set) as a fallback for high latitudes (Verdin and Greenlee, 1996). These DEM based elevation range estimates were found to be more reliable than those reported in GLIMS. Nevertheless the DEM based range estimates do contain some errors due to misalignment between the coordinate systems used by the DEM and the GLIMS and RGI glacier outlines. This misalignment will usually still result in reasonable range estimates, except for islands where any offset can lead to extremely small range estimates. I therefore exclude range estimates below a $10 \mathrm{~m}$ threshold.

For real glaciers, there may be situations where it is not trivial how to divide an ice mass into a distinct number of inventory records. Several valley glaciers may share the same ice field, two valley glaciers may meet in a single tongue, and an ice cap will have many outlet glaciers. The practical 


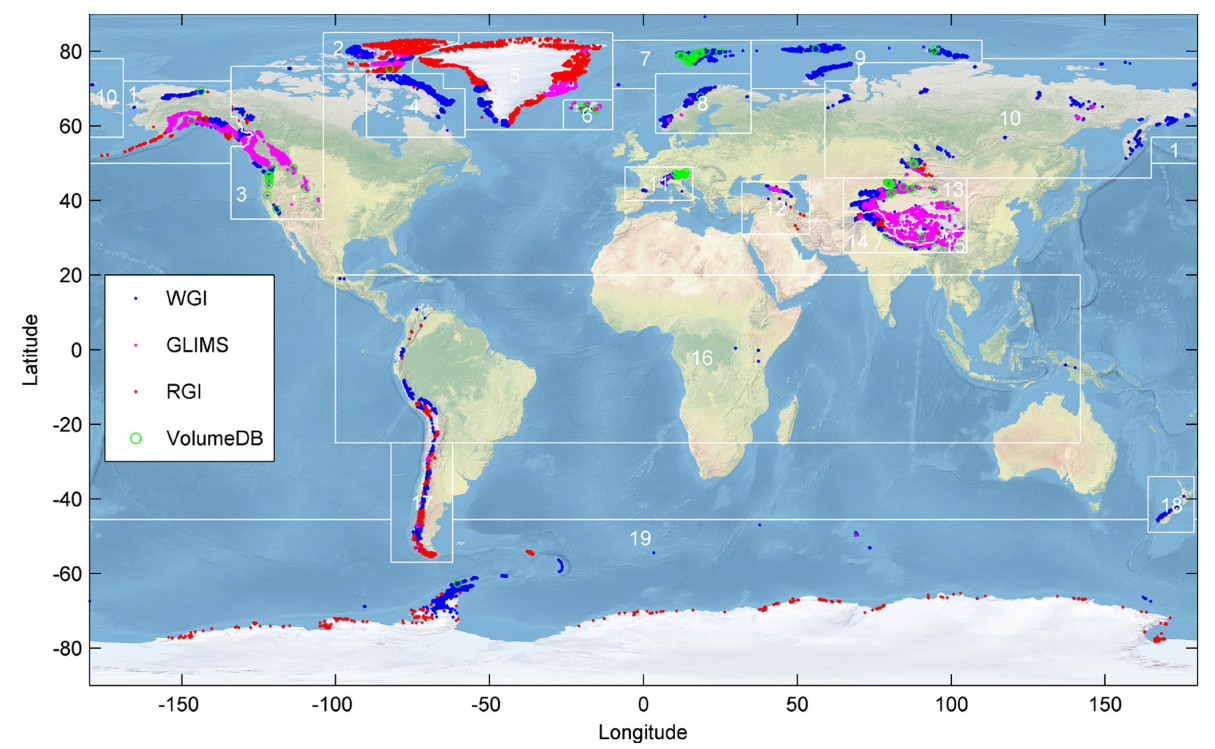

Fig. 1. Spatial distribution of glaciers in the four glacier inventories used in this study. GLIMS glaciers that are already in WGI are not plotted and neither are RGI glaciers overlapping with WGI and GLIMS. VolumeDB refers to the updated Cogley (2012) area volume database used for calibration. White boxes show the regions as defined by Arendt et al. (2012) and region numbers are listed in Tables 2 and 6.

problem of how the area is divided among separate inventory records has an impact on the total volume due to the non-linearity of the volume scaling relationships (see Table 1). The division issue can be particularly important for volume estimates based on the new Randolph Glacier Inventory (RGI) where each record may not have been carefully divided into distinct units because of the vast number of new glacier outlines the RGI contains. Parts of some regions (Alaska, Antarctic and Subantarctic, central Asia, Greenland, low latitudes, New Zealand, Scandinavia and southern Andes) contain outlines for glacier complexes rather than individual glaciers.

I also use a global grid of continentality, determined from ERA40 2-meter temperatures. I, here, define the continentality as the standard deviation of the mean annual cycle (in monthly resolution).

\section{Methods}

The size of individual glaciers is quantified using many different metrics such as length $(L)$, width $(W)$, area $(A)$, volume $(V)$, elevation range $(R)$, and average thickness $(D)$. These quantities are generally correlated so that a large glacier in terms of area is also a large glacier in terms of volume. This has been used to establish scaling relationships between individual size measures such as volume and area, which usually take the form $V=k \cdot A^{\gamma}$ or $\log (V)=\log (k)+$ $\gamma \cdot \log (A)$. The only practical method available to estimate the total volume of all glaciers in the world has relied on this type of scaling, although recently, novel methods have been developed based on ice physics and flux-balance consider- ations which can also be applied globally (Farinotti et al., 2009; Huss and Farinotti, 2012).

Scaling laws can be physically justified, and exponents $(\gamma)$ of 1.375 and 1.25 have been argued to be appropriate for valley glaciers and ice caps, respectively (Bahr et al., 1997). These relationships are designed to capture how the volume of an idealized glacier changes as it grows or shrinks. Of course these idealized assumptions are only approximations, and for real glaciers, other constants and exponents may give a more accurate approximation to their behavior. Further, there is no a priori reason to expect that the same scaling relationship will be appropriate for all glaciers even if the idealized assumptions were to hold. For example, Bahr (1997) considers a distribution of scaling constants. That would imply a globally applicable yield stress, and thus all mountains to have roughly the same slope (Cuffey and Paterson, 2010; Haeberli and Hoelzle, 1995). However, empirical estimates of volume and area support the notion that a near universal scaling law can be applied across a very wide range of sizes, although the scatter indicates (Fig. 2) that applying such scaling laws to individual glaciers can only provide estimates with large uncertainties in the range of $50-200 \%$.

The traditional technique to estimate the scaling law parameters $(\gamma$ and $k)$ is least squares regression in a log-log space (e.g. Chen and Ohmura, 1990; Macheret and Zhuravlev, 1982). This minimizes the squared log deviation misfit function:

$\log \operatorname{mse}(p)=\sum_{i}\left(\log \left(V_{\text {model }}(p, i)\right)-\log \left(V_{\text {obs }, i}\right)\right)^{2}$,

where $i$ is an index in the glacier volume database, $V_{\text {model }}$ is the scaling law with a set of parameters $p$, and $V_{\text {obs }}$ are 

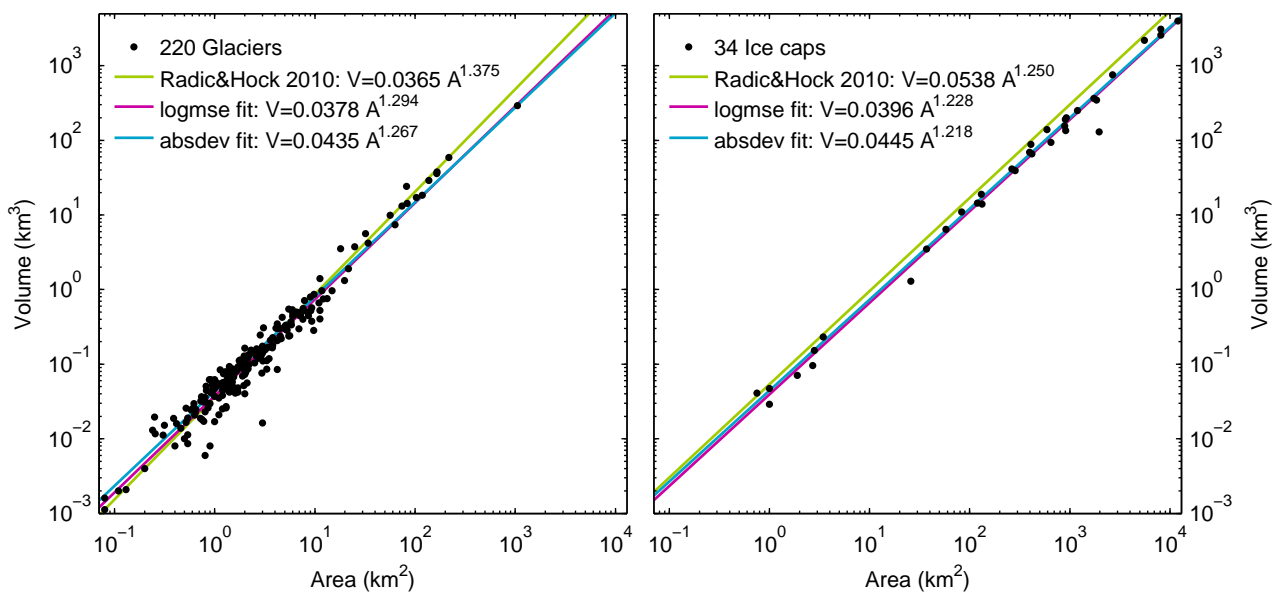

Fig. 2. Area-volume scaling for glaciers (left) and ice caps (right) calibrated to a collection from Cogley (2012). The y-axis is the same so that the smaller volumes for a given area of ice caps can be seen. The fitted lines are from least squares regression of $\log (V)$ and least absolute difference in volume. For comparison, the scaling law used in Radić and Hock (2010) is also shown.

the observed volumes. The model arising from this approach is optimized to minimize the relative misfit for a very wide range of size classes and is heavily biased towards small and medium sized glaciers, for which most observations are available. Alternatively, we can construct a model where the absolute volume misfit is minimized. This calibration strategy is better suited for sea level rise studies, as an error in the volume of a large ice mass is arguably more important than an error in a small ice mass, and is expected to produce better total volume estimates. Least absolute deviation estimators are robust to outliers and particularly useful for asymmetric distributions (Cade and Richards, 1996). On the other hand, the error in the observed volume will scale with the size of the glacier, and in order to minimize the impact from data uncertainties it may be better to minimize log volume misfit as is traditionally done. The relative skill of the two approaches will depend on the size of the calibration dataset, as more samples diminish the importance of noise. The database of volumes has a much higher frequency of the large area glaciers than the full RGI, which reflects a preference for surveying the largest glaciers. To reduce this sampling bias I weigh the misfit by the inverse square root of the area and write the misfit function:

$\operatorname{absdev}(p)=\sum_{i} \frac{\left|V_{\text {model }}(p, i)-V_{\mathrm{obs}, i}\right|}{\sqrt{A_{\mathrm{obs}, i}}}$,

where $A_{\text {obs }}$ is the areas corresponding to $V_{\text {obs }}$. The exact form of this selection bias is hard to quantify, so I have chosen this simple weighing function of area, which makes the area distribution in the volume database more similar to the area distribution in the RGI.

Ice caps may have a different scaling relationship compared to glaciers. I therefore fit scaling laws separately for glaciers and ice caps. Unfortunately not all inventory records have been classified as being either. In order to avoid classifying these glacier records, I additionally calibrate alternative scaling relationships for glacier records that are greater or smaller than $25 \mathrm{~km}^{2}$. This threshold was chosen by examining in the volume database the size range for which there is reasonable overlap between glacier and ice cap volumes. The final global volume estimate is robust to threshold choices in the range from 1 to $250 \mathrm{~km}^{2}$. The scaling relationships applied to the RGI are based almost entirely on the area rule, as the entire RGI inventory lacks glacier vs. ice cap classification save for where I have matched records with the WGI and GLIMS.

The optimal volume area coefficients are shown in Fig. 3 for both the logmse and the absdev misfit functions calibrated over 5 subgroups of ice bodies (ice caps, glaciers, $A>25 \mathrm{~km}^{2}, A<25 \mathrm{~km}^{2}$, and the full database). For any exponent $\gamma$ there is only $k$ which results in exactly the same volume as in the calibration dataset. This means we can reduce the number of free parameters by determining the scaling constant in this manner. As expected, the minimum in the absdev misfit function follows closely the parameter combinations that result in the correct total volume for the calibration dataset, which was my motivation for choosing this method when estimating total volume. The majority of the parameter combinations from Table 1 result in too large a total volume when applied to the volume database (Figs. 2, 3 ). For example, the Radić and Hock (2010) relationships results in $40 \%$ and $53 \%$ too great a volume for glaciers and ice caps, respectively in this sample, as can be seen from how the k-parameters fall in Fig. 3. For small glaciers we see that the misfit minimum does not closely hug the line for a good total volume match (see Fig. 3c, d, e, f). This is due to the large scatter for small glaciers (Fig. 2). It may, therefore, be better to calibrate a separate relationship for large glaciers rather than using a single relationship for all glaciers. 
Table 2. Total glacierized area $\left(\mathrm{km}^{2}\right)$ in each region for three inventories. For RH10 (Radić and Hock, 2010) the closest corresponding regions are shown. RGI contains the best available estimate as the only complete inventory. Numbers in parenthesis mark numbers with known inventory issues, or implied from large disagreement with RGI.

\begin{tabular}{llrrr}
\hline & Region & RGI & WGI/GLIMS & RH10 \\
\hline 1 & Alaska & 89755 & $(54324)$ & $(79260)$ \\
2 & Western Canada and US & 14560 & 13746 & $(21480)$ \\
3 & Arctic Canada (North) & 104873 & $(96761)$ & $(146690)$ \\
4 & Arctic Canada (South) & 40899 & 42586 & \\
5 & Greenland periphery & 87810 & $(123035)$ & $(54400)$ \\
6 & Iceland & 11060 & 11053 & 11005 \\
7 & Svalbard & 33959 & $(36129)$ & 36506 \\
8 & Scandinavia & 2853 & 2960 & 3057 \\
9 & Russian Arctic & 51591 & $(56779)$ & 56781 \\
10 & North Asia & 2933 & $(3693)$ & 2902 \\
11 & Central Europe & 2064 & 2936 & 3045 \\
12 & Caucasus and Middle East & 1354 & 1435 & 1397 \\
13 & Central Asia & 64524 & $(105704)$ & 114330 \\
14 & South Asia (West) & 33861 & 35491 & \\
15 & South Asia (East) & 21819 & $(35152)$ & \\
16 & Low latitudes & 4068 & $(3143)$ & $(7060)$ \\
17 & Southern Andes & 32546 & $(25925)$ & $(29640)$ \\
18 & New Zealand & 1162 & 1157 & 1156 \\
19 & Antarctic and Subantarctic & 133246 & $(95667)$ & $(172740)$ \\
\hline & Total & 734933 & $(747688)$ & 741448 \\
\hline
\end{tabular}

The performance of the alternative calibration strategies (minimizing logmse or absdev) can be tested on surrogate data where we know the area and volume of every glacier. Here I use the estimated volumes from Huss and Farinotti (2012) as the truth in a virtual world. This allows me to replicate different calibration procedures in a Monte Carlo manner and, thus, identify systematic biases and uncertainties in the total volume from different volume area scaling. I draw a small random sample from this data which is used as the calibration data set. I simulate the selection bias in the area volume database by drawing random samples with a probability proportional to the square root of the area. The total volume resulting from the calibrated scaling law is then compared to true total volume in the dataset. I add $3 \%$ standard error to area estimates, and 5\% error to volumes used in the calibration. I separately calibrate scaling laws for areas greater and smaller than $25 \mathrm{~km}^{2}$, mirroring the conditions that will be applied to the RGI dataset. I find that none of the methods show any appreciable bias when compared to the level of uncertainty involved in the scaling law. I find that the absdev misfit function results in the best total volumes, and that restricting the parameter space improves the estimates even further (see Table 3). The estimated standard errors are reduced to $4.6 \%$, and I choose this restricted model and the absdev misfit function in the calibrations that are applied in the following.

The extrapolation of scaling relationships that has been calibrated for glaciers, to entire glacier complexes, is thought to be the dominant source of error. For example, the glacier
Table 3. Root mean square error in global volumes using different calibration methods when tested on the Huss and Farinotti (2012) areas and volumes. $N$ is the size of the calibration data set, and $q=\Sigma V_{\mathrm{obs}} / \Sigma A_{\mathrm{obs}}^{\gamma}$

\begin{tabular}{lrr}
\hline $\begin{array}{l}\text { Misfit function, } \\
\text { model }\end{array}$ & $\begin{array}{r}A<25 \mathrm{~km}^{2} \\
N=211\end{array}$ & $\begin{array}{r}A>25 \mathrm{~km}^{2} \\
N=41\end{array}$ \\
\hline logmse, $k \cdot A^{\gamma}$ & $9.9 \%$ & $9.6 \%$ \\
absdev, $k \cdot A^{\gamma}$ & $6.7 \%$ & $8.3 \%$ \\
logmse, $q \cdot A^{\gamma}$ & $5.4 \%$ & $10.4 \%$ \\
absdev, $q \cdot A^{\gamma}$ & $4.7 \%$ & $8.1 \%$ \\
\hline
\end{tabular}

complex representation of Arctic Canada (South) in RGI v1 results in a $\sim 80 \%$ greater volume than the subdivided representation in RGI v2. Similarly, grouping all glaciers in the Swiss Aletsch region into a single glacier complex increases the estimated volume from volume area scaling by $70 \%$. I estimate the size of this bias using the Monte Carlo approach as above but restricting the calibration to regions where the inventory outlines correspond to single glaciers rather than large complexes. I then apply the scaling laws to the RGI v2 area database. I find that the root mean squared error on the global total volume increases to $20 \%$, and the bias increases to $+15 \%$ when I exclude regions with glacier complexes (Alaska, Antarctic and Subantarctic, central Asia, Greenland, low latitudes, New Zealand, Scandinavia and southern Andes) from the calibration data.

For some glaciers there may be data on several size measures simultaneously, and there are thus several options to estimate missing size metrics. For example, we can estimate $V$ from either $L$ or $A$, or both. Here I use multiple linear regression to utilize as many predictors as possible in the scaling law used for imputation. Motivated by Bahr et al. (1997), the regressions are done in log-log space. For each glacier only a subset of metrics exists in the inventory and among these the best set of predictors is chosen using a model selection criterion which compares the predictive skill against withheld data in a fourfold cross validation (Arlot and Celisse, 2010). I use the mean squared prediction error of the logged volumes as a validation metric, rather than using the misfit function. The various size measures are multicollinear by nature, which may potentially affect the performance of regressions, and regularization can be needed. I did not use ridge regression techniques as this introduces a bias, and did not improve the skill in this particular study. Cross validation against withheld data is an efficient guard against multicollinearity and overfitting.

Maritime glaciers are characterized by having a much greater mass turnover than continental glaciers. This will influence the thickness directly, but also indirectly through temperature profiles and water availability. The mass turnover is strongly determined by the vertical mass balance gradient, which will be inversely related to tempera- 


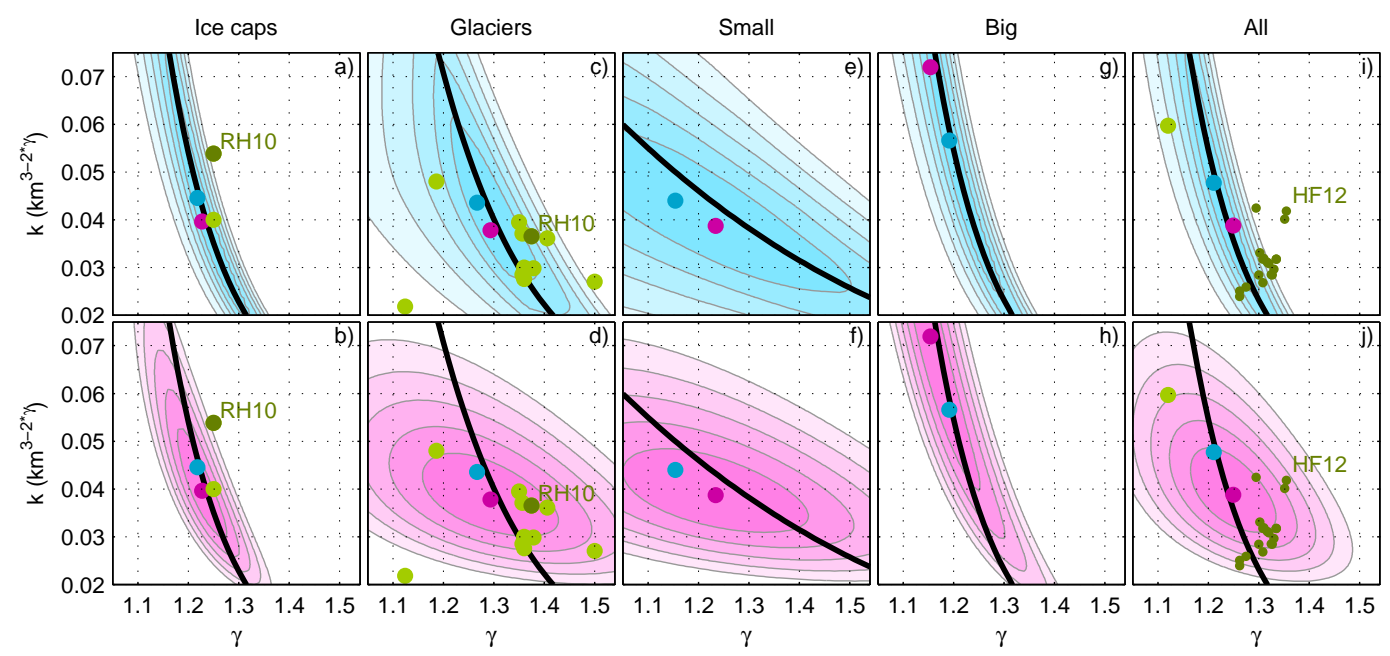

Fig. 3. Area-volume scaling law exponents and coefficients for 5 different groups of glaciers and ice caps. Background shading show the misfit functions contoured for 0.2 increase in the $\log$ (misfit). Black lines show the parameter combinations that result in the correct total volume for the calibration volume database. Top row uses a weighted absolute deviation misfit function in cyan, and bottom row uses a squared log volume misfit in magenta. Cyan and Magenta dots show the locations of the corresponding minimum misfit. Green dots show the scaling laws in Table 1 for comparison. The recent RH10 (Radić and Hock, 2010) and HF12 (Huss and Farinotti, 2012) scaling laws are highlighted with a darker shade of green. Small and Big use a $25 \mathrm{~km}^{2}$ area threshold.

ture variability and thus continentality as this greatly influences how many positive degree days will be available for melt at lower elevations. Similar considerations led Oerlemans (2005) to use total annual precipitation as a proxy for vertical mass balance gradient. However, continentality is spatially coherent over much larger distances, and probably shows a closer correspondence unless very local precipitation data is available at each glacier. Further, Braithwaite (1985) provided the physical justification for linking temperature variability to vertical mass balance gradient if a constant temperature lapse rate is assumed. I therefore include continentality $(C)$ as a potential predictor in the volume scaling models.

To summarize, I attempt to optimally predict total volume from a set of potential predictors: $A, R, L$, and $C$. I exclude $W$ because it severely restricts the potential number of records in the validation sample where all measures must be present in order to make a fair comparison of models. The meaning of length is ambiguous for ice caps and is therefore excluded for the ice cap scaling laws. Calibrating the models, results in the empirical scaling laws listed in Table 4 for the weighted least absolute deviation estimator. The cross validation is not the same for the RGI and WGI/GLIMS as different subsets are set aside for the validation. The scaling relationships in Table 4 are ordered by their performance in the cross validations, and are applied in the listed order to the RGI. First the ice cap and glacier relationships are applied to all records that have a classification. Then the large and small relationships are applied. Relationships that perform worse than pure area volume scaling are not used.

\section{Results and discussion}

From the set of best scaling laws (Table 3), I calculate the volume of every glacier in the inventory and calculate the regional total (Table 4). Volumes are reported in units of meters sea level equivalent (SLE) assuming an ice density of $900 \mathrm{~kg} \mathrm{~m}^{-3}$ and an ocean area of $362 \times 10^{8} \mathrm{~km}^{2}$. I find that the total volume of all glaciers and ice caps range from 0.33 to $0.36 \mathrm{~m}$ SLE, depending on the choice of calibration method and inventory (Table 5). This is substantially less than the $0.60 \pm 0.07 \mathrm{~m}$ SLE from Radić and Hock (2010). Different inventories cannot explain this large difference and the issue must be with the different scaling laws applied. The Radić and Hock (2010) relationships result in $40 \%$ and $53 \%$ too great a total volume for glaciers and ice caps, respectively, when applied to the volume database from this study, as can be seen from how the k-parameters fall in Fig. 3. In Fig. 2 we see that the Radić and Hock (2010) ice cap volumearea scaling law has a positive bias relative to observations, and that the glacier scaling law has a steeper slope, which can result in large volumes beyond the calibration range. The unit of the constant $k$ is length ${ }^{(3-2 \gamma)}$. It is therefore problematic to mix the scaling constant determined from one study, and directly apply it to a scaling law using another exponent. Nevertheless this is sometimes done (e.g. Radić and Hock, 2010; Slangen and van de Wal, 2011). The constant $k$ can also be interpreted more intuitively as the typical thickness of a glacier with unit area. Extrapolating the scaling laws in Fig. 2, we see that any small change in the slope of the scaling law will have a large impact on the volume (and thus average thickness) of a $1 \mathrm{~m}^{2}$ sized glacier/ice cap (which would 
Table 4. Volume scaling relationship obtained from minimizing the absolute volume deviation with the scaling constant constrained by total volume. These relationships are expressed in Kelvin, $\mathrm{km}, \mathrm{km}^{2}$ and $\mathrm{km}^{3}$ units. More decimal places are retained than is significant to facilitate conversion to other units. The scaling laws within each group are ordered by performance in the RGI and secondly in the WGI/GLIMS cross validations.

\begin{tabular}{ll}
\hline & Scaling relationships \\
\hline Ice caps & $V=0.0552 R^{0.124} A^{1.20}$ \\
& $V=0.0432 A^{1.23}$ \\
Glaciers $\quad V=0.0413 R^{-0.0565} A^{1.3}$ \\
& $V=0.0433 A^{1.29}$ \\
& $V=0.0087 R^{-0.30} A^{1.37} L^{0.023} C^{0.62}$ \\
& $V=0.0134 A^{1.32} C^{0.49}$ \\
& $V=0.0433 A^{1.29} L^{0.0019}$ \\
$A>25 \mathrm{~km}^{2} \quad V=0.0746 R^{0.175} A^{1.16}$ & \\
& $V=0.0540 A^{1.20}$ \\
& $V=0.0175 R^{-0.15} A^{1.33} C^{0.34}$ \\
& $V=0.0385 R^{-0.20} A^{1.29}$ \\
& $V=0.0435 A^{1.23}$ \\
& $V=0.0434 A^{1.24} L^{-0.0042}$ \\
\hline
\end{tabular}

be well beyond the minimum of the plotted range, and far smaller than any real glacier). The uncertainty in the volumearea scaling is huge for a $1 \mathrm{~m}^{2}$ ice cap, where the regression is virtually unconstrained, and thus mixing constants and exponents from different studies can introduce a large bias. Using $\mathrm{km}^{2}$ units or expressing the area with respect to a typical reference area greatly reduces the potential error arising from mixing constants and exponents from different studies.

Theoretical exponents are greater than what the regressions to the volume database yield regardless of misfit function (Table 2, Fig. 3). My interpretation is that there is a systematic tendency towards less viscous basal ice for larger ice masses, which would reduce the exponent. A too large exponent leads to a positive bias in the total volume if it is applied to glaciers that are much greater than those in the calibration dataset. This can be a very important total volume estimate as the volume is concentrated in the largest ice masses.

Regional estimates of volume are shown in Table 4 . There are considerable discrepancies between the RGI and WGI/GLIMS based on volume estimates for Arctic Canada (South), southern Andes, South Asia (East), and Svalbard. These differences can largely be explained by serious deficiencies in the WGI/GLIMS inventory (see Table 2). For example, the two largest ice caps in Svalbard containing $\sim 8 \mathrm{~mm}$ SLE (Dowdeswell et al., 1986; Zhuravlev, 1985) are not represented in the WGI/GLIMS database. The regional volume estimates can also be validated against estimates where the major fraction of the volume has been estimated using survey methods. The only such estimate I have been able to find is Björnsson and Pálsson (2008), who estimated the total volume of ice in Iceland to be $9 \mathrm{~mm}$ SLE,
Table 5. Calculated total volume of two glacier inventories and three methods of calibrating the scaling law. The robust least absolute deviation estimate based on RGI is considered to be the best as there are serious inventory deficiencies with WGI/GLIMS (see text and Table 1).

\begin{tabular}{lrr}
\hline $\begin{array}{l}\text { Calibration strategy, } \\
\text { model }\end{array}$ & $\begin{array}{r}\text { RGI } \\
\text { (m SLE) }\end{array}$ & $\begin{array}{r}\text { WGI/GLIMS } \\
\text { (m SLE) }\end{array}$ \\
\hline logmse, $k \cdot A^{\gamma}$ & 0.36 & 0.33 \\
absdev, $k \cdot A^{\gamma}$ & 0.35 & 0.33 \\
logmse, $q \cdot A^{\gamma}$ & 0.36 & 0.34 \\
absdev, $q \cdot A^{\gamma}$ & 0.35 & 0.34 \\
\hline$q=\Sigma V_{\text {obs }} / \Sigma A_{\text {obs }}^{\gamma}$ & &
\end{tabular}

which compares well with the $8.7 \mathrm{~mm}$ SLE estimated here. It should be noted, however, that the 4 largest Icelandic ice caps are included in the calibration dataset.

The RGI contains glacier complexes rather than individual glaciers in some regions. However, in some cases the RGI has been divided more strictly than the volume database. For example, Devon ice cap has been estimated to hold $\sim 4100 \mathrm{~km}^{3}$ of ice (Dowdeswell et al., 2004). In RGI, Devon ice cap is represented by 192 separate records, and applying the scaling laws (Table 2) on these records results in a volume of $3550 \mathrm{~km}^{3}$, whereas treating all these records as a single ice cap results in a volume of $4410 \mathrm{~km}^{3}$. For comparison, Huss and Farinotti (2012) estimate $6200 \mathrm{~km}^{3}$. It would lead to a negative bias in scaling based estimates, if ice caps systematically have been subdivided in the inventory.

I find that including continentality and vertical range does improve the fit of area-volume scaling in the cross validation (Table 4). Continentality has a large natural range, enters with larger exponents, and consequently is found to have a quite strong impact on the estimated volumes. Range enters the relationships with exponents close to zero and thus acts as a small correction to traditional area volume scaling. Care should be taken when interpreting the scaling exponents when more than one size measure is included, as these tend to be highly collinear. It is possible to argue for both positive and negative exponents for $R$ and $C$. More maritime glaciers tend to have greater mass balance gradients and larger mass throughput, and I would, therefore, expect them to be thicker to accommodate this greater flux. However, maritime glaciers are also characterized by a warmer thermal regime which would allow ice to flow more easily and consequently the glacier would not have to be as thick to accommodate a given flux. The continentality exponents in Table 4 suggest that the ice rheological effect may be dominant for small glaciers, whereas the for large ice masses the effect of continentality on the vertical mass-balance gradient may be more important. Table 4 indicates that small glaciers tend to be thinner when they span a greater vertical range. A greater vertical range implies a greater slope, a 
Table 6. Estimated total volume of ice (mm SLE) by region (see Fig. 1) for the two inventories. Numbers in parenthesis mark numbers with known inventory deficiencies (see text). The volumes for the closest corresponding regions estimated by RH10 (Radić and Hock, 2010) and HF12 (Huss and Farinotti, 2012) are shown for comparison.

\begin{tabular}{llrrrr}
\hline & Region & RGI & WGI/GLIMS & RH10 & HF12 \\
\hline 1 & Alaska* & 44.6 & $(23.2)$ & $(68)$ & 50.7 \\
2 & Western Canada and US & 2.6 & 2.6 & $(4.7)$ & 2.5 \\
3 & Arctic Canada (North) & 61.7 & $(65.5)$ & $(199)$ & 85.4 \\
4 & Arctic Canada (South) & 15.2 & 21.6 & & 24.4 \\
5 & Greenland periphery* & 47.0 & $(68.0)$ & $(44)$ & 47.3 \\
6 & Iceland & 8.7 & 8.9 & 12 & 11.0 \\
7 & Svalbard & 13.3 & $(23.8)$ & 26 & 24.0 \\
8 & Scandinavia* & 0.8 & 0.5 & 0.56 & 0.6 \\
9 & Russian Arctic & 33.8 & $(32.1)$ & 43 & 41.8 \\
10 & North Asia & 0.5 & $(0.6)$ & 0.42 & 0.3 \\
11 & Central Europe & 0.3 & 0.4 & 0.48 & 0.3 \\
12 & Caucasus and Middle East & 0.2 & 0.2 & 0.22 & 0.2 \\
13 & Central Asia* & 23.7 & $(20.0)$ & 31 & 12.5 \\
14 & South Asia (West) & 9.5 & 9.8 & & 8.0 \\
15 & South Asia (East) & 4.1 & $(5.1)$ & & 3.3 \\
16 & Low latitudes* & 0.3 & $(0.2)$ & $(0.86)$ & 0.4 \\
17 & Southern Andes* & 11.7 & $(6.8)$ & $(20)$ & 16.6 \\
18 & New Zealand* & 0.3 & 0.2 & 0.21 & 0.2 \\
19 & Antarctic and Subantarctic* & 75.1 & $(53.6)$ & $(178.9)$ & 93.1 \\
\hline
\end{tabular}

${ }^{*}$ Regions where parts of the RGIv2 outlines are representing glacier complexes.

greater driving stress, and greater velocities which allows a thinner glacier to accommodate the same mass flux (Cuffey and Paterson, 2010; Haeberli and Hoelzle, 1995). However, greater vertical extent will span a larger range of temperatures and have greater mass balance difference between top and bottom. Consequently, the flow at the equilibrium line would have to accommodate a greater flux and the ice thickness would have to be greater. This latter effect appears to dominate for large glaciers range exponents in Table 4.

\section{Conclusions}

I calibrate scaling laws for the specific purpose of estimating the total volume of all glaciers on Earth. This is applied individually to each record in the Randolph Glacier Inventory which is the first globally complete inventory of glaciers and ice caps. I estimate that the total volume of all glaciers in the world (or more accurately in the inventory) is $0.35 \pm 0.07 \mathrm{~m}$ SLE. This is substantially less than the $0.60 \pm 0.07 \mathrm{~m} \mathrm{SLE}$ from Radic and Hock (2010). It is also less than, but compatible with, the $0.43 \pm 0.06 \mathrm{~m}$ SLE estimated in Huss and Farinotti (2012) for the same inventory. Excluding the peripheral glaciers of the Greenland and Antarctic ice sheets results in $0.23 \mathrm{~m}$ SLE. This is comparable to the $0.24 \pm 0.03 \mathrm{~m}$ SLE estimated by Raper and Braithwaite (2005a) using an approach which was questioned by Meier et al. (2005) and further discussed in Raper and Braithwaite (2005b). The discrepancy with Radić and Hock (2010) cannot be fully explained by differences due to inventory upscaling alone. I identify a source of positive bias in most of the published scaling relationships. For example, the scaling relationship used by Radić and Hock (2010) yield 40-50\% too large a total volume when applied to the volume database used in this study (Fig. 3). The regional volume estimates are likely biased high in regions where the RGI contains a significant fraction of the area as glacier complexes because the volume scaling was calibrated on single glacier/ice cap units. Using a Monte Carlo test against surrogate data, I estimate that this remaining issue may lead to a $\sim 5 \mathrm{~cm}$ positive bias in the global volume estimate.

The true level of uncertainty is probably greater than the confidence intervals that any single study imply, considering the unsatisfactory disagreement between various published global glacier volume estimates, and regional discrepancies are even larger. This situation can be improved by collecting more thickness data, both from the field and from existing literature. There are probably hundreds of glaciers and ice caps that have been measured, but which have yet to be included in the volume database used in this study. Additionally, very small "glaciers" $\left(<0.1 \mathrm{~km}^{2}\right)$ are not fully represented in all the inventories, and there may, therefore, be a missing contribution in the order of $\sim 10 \%$ from all inventory based glacier volume estimates (Bahr and Radić, 2012), including mine.

The total volume stored in glaciers and ice caps is dominated by relatively few very large and thick ice masses. Figure 4 shows that roughly $85 \%$ of the total ice volume is stored in $\sim 1000$ RGI glaciers greater than $100 \mathrm{~km}^{2}$, in agreement with Huss and Farinotti (2012). The statistical approach 


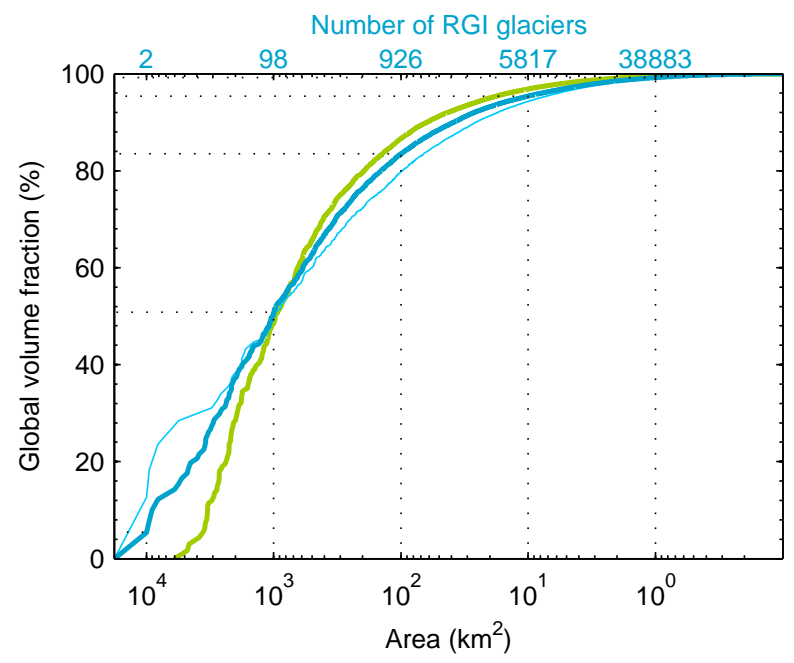

Fig. 4. The volume fraction stored in all the glaciers larger than a given area. Dark cyan shows the results of this study, and thin bright cyan excluding regions with many glacier complexes in RGI v2 (see Table 6). The distribution from Huss and Farinotti (2012) is shown in green.

of Bahr and Radić (2012) yield a smaller volume fraction in the order of $\sim 70 \%$, which may indicate differences in the area distributions between the studies. This is stored in a much more manageable number of glaciers and ice caps considering that large ice caps frequently are divided into several RGI records. For example, Devon ice cap is represented by 192 RGI records and 19 of these are greater than $100 \mathrm{~km}^{2}$. It may, therefore, be feasible to get the volume of the majority of these large ice masses on an individual basis through direct measurements or through other detailed studies. This would reduce the uncertainty on the global estimate substantially. Sophisticated techniques as used by Huss and Farinotti (2012), and the simpler area-range-volume scaling used in this study, relies on accurate elevation data and proper alignment of glacier outlines with the underlying DEM. Both methods would benefit greatly from additional homogenization of the inventory data.

\section{Supplementary material related to this article is available online at: http://www.the-cryosphere.net/7/141/ 2013/tc-7-141-2013-supplement.zip.}

Acknowledgements. The research was partly funded by NSFC no. 41076125, the Danish Strategic Research Council through its support of Centre for Regional Change in the Earth System (CRES; www.cres-centre.dk) under contract DSF-EnMi no. 09-066868, the Nordic Top-level Research Initiative, ERC Advanced Grant no 246815 (WATERundertheICE), and a Inge Lehmann travel grant. G. Cogley, A. Arendt, and M. Huss for data and helpful correspondence. This publication is contribution no. 11 of the Nordic Centre of Excellence SVALI, Stability and Variations of Arctic land Ice, funded by the Nordic Top-level Research Initiative.

Edited by: J. O. Hagen

\section{References}

Adhikari, S. and Marshall, S. J.: Glacier volume-area relation for high-order mechanics and transient glacier states, Geophys. Res. Lett., 39, L16505, doi:10.1029/2012GL052712, 2012.

Arendt, A., Bolch, T., Cogley, J. G., Gardner, A., Hagen, J.-O., Hock ,R., Kaser, G., Pfeffer, W. T., Moholdt, G., Paul, F., Radić, V., Andreassen, L., Bajracharya, S., Beedle, M., Berthier, E., Bhambri, R., Bliss, A., Brown, I., Burgess, E., Burgess, D., Cawkwell, F., Chinn, T., Copland, L., Davies, B., de Angelis, H. , Dolgova, E., Filbert, K., Forester, R., Fountain, A., Frey, H., Giffen, B., Glasser, N., Gurney, S., Hagg, W., Hall, D., Haritashya, U. K., Hartmann, G., Helm, C., Herreid, S., Howat, I., Kapustin, G., Khromova, T., Kienholz, C., Koenig, M., Kohler, J., Kriegel, D., Kutuzov, S., Lavrentiev, I., LeBris, R., Lund, J., Manley, W., Mayer, C., Miles, E., Li, X., Menounos, B., Mercer, A., Moelg, N., Mool, P., Nosenko, G., Negrete, A., Nuth, C., Pettersson, R., Racoviteanu, A., Ranzi, R., Rastner, P., Rau, F., Rich, J., Rott, H., Schneider, C., Seliverstov, Y., Sharp, M., Sigur`sson, O., Stokes, C., Wheate, R., Winsvold, S., Wolken, G., Wyatt, F., and Zheltyhina, N.: Randolph Glacier Inventory [v2.0]: A Dataset of Global Glacier Outlines. Global Land Ice Measurements from Space, Boulder Colorado, USA, Digital Media (with area corrections downloaded 2012), 2012.

Arlot, S. and Celisse, A.: A survey of cross-validation procedures for model selection, Statistics Surveys, 4, 40-79, 2010.

Armstrong, R., Raup, B., Khalsa, S. J. S., Barry, R., Kargel, J., Helm, C., and Kieffer, H.: GLIMS glacier database. Boulder, Colorado USA: National Snow and Ice Data Center, Digital media, (downloaded February), 2012.

Bahr, D. B.: Global distributions of glacier properties: a stochastic scaling paradigm, Water Res., 33, 1669-1679, 1997.

Bahr, D. B. and Radic', V.: Significant contribution to total mass from very small glaciers, The Cryosphere, 6, 763-770, doi:10.5194/tc-6-763-2012, 2012.

Bahr, D. B., Meier, M. F., and Peckham, S.: The physical basis of glacier volume-area scaling, J. Geophys. Res., 102, 2035520362, 1997.

Björnsson, H. and Pálsson, F.: Icelandic glaciers, Jökull, 58, 365386, 2008.

Braithwaite, R. J: Calculation of degree-days for glacier-climate research, Zeitschrift für Gletscherkunde und Glazialgeologie, 20, 1-8, 1985.

Cade, B. S. and Richards, J. D.: Permutation tests for least absolute deviation regression, Biometrics, 52, 886-902, 1996.

Chen, J. and Ohmura, A.: Estimation of Alpine glacier water resources and their change since the 1870's, IAHS Publ., 193, 127135, 1990.

Chizhov, O. P. and Kotlyakov, V. M.: Studies of the Antarctic and present-day concepts of global glaciation, Ann. Glaciol., 3, 5053, 1983.

Church, J. A., Gregory, J. M., Huybrechts, P., Kuhn,M., Lambeck, K., Nhuan, M. T., Qin, D., and Woodworth, P. L.: Changes in 
sea level, in: Climate Change: The Scientific Basis, Contribution of Working Group I to the Third Assessment Report of the Intergovernmental Panel on Climate Change, edited by:Houghton, J. T. , Ding, Y., Griggs, D. J., Noguer, M., van der Linden, P., Dai, X., Maskell, K., and Johnson, C. I., Cambridge University Press, Cambridge, United Kingdom and New York, NY, USA, 639-693, 2001.

Cogley, J. G.: The future of the world's glaciers, in: The Future of the World's Climate, edited by: Henderson-Sellers, A. and McGuffie, K., Elsevier, chap. 8, 205-218, doi:10.1016/B978-012-386917-3.00008-7, 2012.

Cuffey K. M. and Paterson, W. S. B.: The Physics of Glaciers, Fourth Edition Academic Press ISBN: 9780123694614, 2010.

Dowdeswell, J. A., Drewry, D. J., Cooper, A. P. R., Gorman, M. R., Liestøl, O., and Orheim, O.: Digital mapping of the Nordaustlandet ice caps from airborne geophysical investigations, Ann. Glaciol., 8, 51-58, 1986.

Dowdeswell, J. A., Benham, T. J., Gorman, M. R., Burgess, D., and Sharp, M. J.: Form and flow of the Devon Island Ice Cap, Canadian Arctic, J. Geophys. Res., 109, F02002, doi:10.1029/2003JF000095, 2004.

Driedger, C. L. and Kennard, P. M.: Ice Volumes on Cascade Volcanoes: Mount Rainer, Mount Hood, Three Sisters, Mount Shasta, Available from Supt Doc, USGPO, Wash DC 20402, USGS Professional Paper 1365, 28 p., 1986.

Erasov, N. V.: Method to determine the volume of mountain glaciers (in Russian), Mater, Glyatsiol, Issled, Khronika, Obsuzhdniya, 14, 307-308, 1968.

Farinotti, D., Huss, M., Bauder, A., Funk, M., and Truffer, M.: A method to estimate ice volume and ice-thickness distribution of alpine glaciers, J. Glaciol., 55, 422-430, 2009.

Haeberli, W. and Hoelzle, M.: Application of inventory data for estimating characteristics of and regional climate-change effects on mountain glaciers: a pilot study with the European Alps, Ann. Glaciol., 21, 206-212, 1995.

Huss, M. and Farinotti, D.: Distributed ice thickness and volume of all glaciers around the globe, J. Geophys. Res., 117, F04010, doi:10.1029/2012JF002523, 2012.

Jarvis A., Reuter, H. I., Nelson, A., and Guevara, E.: Hole-filled seamless SRTM data V4, International Centre for Tropical Agriculture (CIAT), available at: http://srtm.csi.cgiar.org, 2008.

Leclercq, P. W., Oerlemans, J., and Cogley, J. G.: Estimating the glacier contribution to sea-level rise over the period 1800-2005, Surv. Geophy., 32, 519-535, doi:10.1007/s10712-011-9121-7, 2011.

Lemke, P., Ren, J., Alley, R. B., Allison, I., Carrasco, J., Flato, G., Fujii, Y., Kaser, G., Mote, P., Thomas, R. H., and Zhang, T.: Observations: Changes in Snow, Ice and Frozen Ground, in: Climate Change 2007: The Physical Science Basis, Contribution of Working Group I to the Fourth Assessment Report of the Intergovernmental Panel on Climate Change, edited by: Solomon, S., Qin, D., Manning, M., Chen, Z., Marquis, M., Averyt, K. B., Tignor, M., and Miller, H. L., Cambridge University Press, Cambridge, United Kingdom and New York, NY, USA, 2007.

Macheret, Y. Y. and Zhuravlev, A. B.: Radio echo-sounding of Svalbard glaciers, J. Glaciol., 28, 295-314, 1982.

Macheret, Y. Y., Zhuravlev, A. B., and Bobrova, L .I.: Tolshchina, podlednyy rel'yef i ob'yem lednikov Shpitsbergena po dannym radiozondirovaniya [Thickness, subglacial relief and volume of
Svalbard glaciers based on radio echo-sounding data], Materialy Glyatsiologicheskikh Issledovaniy, Khronika, Obsuzhdeniya, 51, 49-63, 1984.

Macheret, Y. Y., Cherkasov, P. A., and Bobrova, L. I.: Tolschina i ob'em lednikov djungarskogo alatau po danniy aeroradiozondirovaniya, Materialy Glyatsiologicheskikh Issledovanii: Khronika, Obsuzhdeniya, 62, 59-71, 1988.

Meier, M. F. and Bahr, D. B.: Counting glaciers: Use of scaling methods to estimate the number and size distribution of the glaciers in the world, edited by: Hanover, N. H., CRREL Spec. Rep., US Army, 89-95, 1996.

Meier, M. F., Bahr, D. B., Dyurgerov, M. B., and Pfeffer, W. T.: Comment by M.F. Meier et al. on "The potential for sea level rise: New estimates from glacier and ice cap area and volume distributions", edited by: Raper, S. C. B. and Braithwaite, R. J., Geophys. Res. Lett., 32, L17501, doi:10.1029/2005GL023319, 2005.

Mitrovica, J. X. and Milne, G. A.: On post-glacial sea level: I. General theory, Geophys. J. Int. 154, 253-267, 2003.

Oerlemans, J.: Extracting a climate signal from 169 glacier records. Science, 308, 675-677, 2005.

Radić, V. and Hock, R. : Regional and global volumes of glaciers derived from statistical upscaling of glacier inventory data, J. Geophys. Res., 115, F01010, doi:10.1029/2009JF001373, 2010.

Radić, V., Hock, R., and Oerlemans, J.: Volume area scaling vs flowline modelling in glacier volume projections, Ann. Glaciol., 46, 234-240, 2007.

Raper, S. C. B. and Braithwaite, R. J.: The potential for sea level rise: New estimates from glacier and ice cap area and volume distribution, Geophys. Res. Lett., 32, L05502, doi:10.1029/2004GL021981, 2005a.

Raper, S. C. B. and Braithwaite, R. J.: Reply to comment by Meier, M. F. et al. on "The potential for sea level rise: New estimates from glacier and ice cap area and volume distributions", Geophys. Res. Lett., 32, L17502, doi:10.1029/2005GL023460, 2005b.

Shiyin, L., Wenxin, S., Yongping, S., and Gang, L.: Glacier changes since the Little Ice Age maximum in the western Qilian Shan, northwest China, and consequences of glacier runoff for water supply, J. Glaciol., 49, 117-124, 2003.

Slangen, A. B. A., Katsman, C. A., van de Wal, R. S. W., Vermeersen, L. L. A., and Riva, R. E. M.: Towards regional projections of twenty-first century sea-level change based on IPCC SRES scenarios, Clim. Dynam., 38, 1191-1209, doi:10.1007/s00382-011-1057-6, 2011.

Van de Wal, R. S. W. and Wild, M.: Modelling the response of glaciers to climate change by applying volume-area scaling in combination with a high resolution GCM, Clim. Dynam., 18, 359-366, 2001.

Verdin, K. L. and Greenlee, S. K: Development of continental scale digital elevation models and extraction of hydrographic features. In: Proceedings, Third International Conference/Workshop on Integrating GIS and Environmental Modeling, Santa Fe, New Mexico, 21-26 January, National Center for Geographic Information and Analysis, Santa Barbara, California, 1996.

WGMS and NSIDC: World Glacier Inventory, Compiled and made available by the World Glacier Monitoring Service, Zurich, Switzerland, and the National Snow and Ice Data Center, Boulder CO, USA Digital Media, updated: 2012. 
Yafeng, S., Zongtai, W., and Chaohai, L.: Note on the glacier inventory in Qilian Shan Mountains, in: Glacier Inventory of China, 1, Qilian Mountains, Lanzhou, Institution of Glaciology and Geocryology, 1-9, 1981.

Zhuravlev, A. B.: Korrelyatsionniy metod otsenki zapasov l'da v lednikakh, Materialy Glyatsiologicheskikh Issledovaniy, 52, 241-249, 1985.
Zhuravlev, A. V.: The relation between glacier area and volume, in: Data of Glaciological Studies, vol. 40, edited by: Avsyuk, G. A. and Balkema, A. A., Rotterdam, The Netherlands, Russ. Transl. Ser., 67, 441-446, 1988. 